\title{
Preventing Radicalization in the UK: Expanding the Knowledge-Base on the Channel Programme
}

\section{Amy Thornton and Noémie Bouhana}

\section{Department of Security and Crime Science, University College London}

Accepted on $10^{\text {th }}$ May 2017

\section{Abstract}

The Channel programme is part of the Prevent Strategy, one of the four strands of the UK counter-terrorism strategy known as CONTEST. While the programme has been running since 2007 and thousands of purportedly 'vulnerable' individuals are referred to the programme each year, there are still gaps in public knowledge about the programme, and this paper seeks to fill some of those gaps while raising issues to consider in the future. With empirical data from interviews with individuals who have worked on the Channel programme, issues discussed include the type of individuals who are placed onto the programme, the suitability of intervention providers who aim to assist these vulnerable individuals, and the vital role of schools and the community in the success of the programme. The way in which the programme is designed and framed is of vital importance, as the mechanisms by which a deradicalisation programme should work are very different from those which a counter-radicalisation programme should employ. Finally suggestions are made for future empirical work in order to be able to understand and evaluate Channel. Introduction

The issue of embedding prevention within the police service and wider governmental agencies is of particular importance when considering attempts to prevent and counter radicalisation and terrorism in the UK. The Prevent Strategy, one of the four strands of the 
UK counter-terrorism strategy known as CONTEST, aims to stop individuals becoming terrorists or otherwise coming to support terrorism (HM Government 2011). Among Prevent's most high-profile components is the multi-agency Channel programme, which seeks to "safeguard children and adults from being drawn into committing terrorist-related activity" (HM Government 2012b:2). Channel sets out to pre-emptively identify and intervene with individuals who are thought to be 'vulnerable' to radicalisation or who are believed to be in the process of being radicalised, before they fully adopt a terrorist ideology and go on to commit terrorism-related activity. Since its inception, Channel has been a subject of much interest and no little controversy, not only because the broader Prevent Strategy has been, from the start, a contested approach which has come to be perceived as something of a damaged brand (Elshimi 2016; Kundnani 2009), but also because concrete, open information about Channel itself - its logic, design, implementation, success measures and outcomes - remains thin on the ground. Yet, given that the recent UK CounterTerrorism and Security Act 2015 places a duty on a number of specified authorities, including schools and universities, to "have due regard to the need to prevent people from being drawn into terrorism" (Section 26), and given the uneasiness with which this new obligation has been received (O'Donnell 2015), the need for information about the aims and means of Prevent's flagship programme seems more germane than ever. Beyond these essentially British concerns, Channel has also been looked upon as an example to follow by similar programmes operating abroad, whose aims have ranged from demobilisation to full 'deradicalisation' (Institute for Strategic Dialogue 2010), both from a preventative standpoint (e.g. when implemented within community settings) or with a more reactive outlook (e.g. when implemented within institutions such as prisons). To set the stage, the present paper provides a brief discussion of issues associated with deradicalisation and 
counter-radicalisation programmes generally, followed by an overview of Channel more specifically, before presenting the findings of a qualitative study involving interviews with professionals involved in the programme. The main aim of this article is to try and improve the open-source knowledge-base on Channel, which to date is severely lacking, and hence to contribute to a more informed debate about Prevent duties, old and new.

\section{Counter-radicalisation, deradicalisation and disengagement}

Over the past decade, so-called counter-radicalisation and deradicalisation programmes have proliferated, whether administered by governmental agencies, NGOs or community organisations, with differing levels of official oversight. Where stated, the aims of these programmes can encompass such disparate objectives as individual 'immunisation' against radicalising influence, disengagement from terrorist activity, or rehabilitation and demobilisation from a terrorist organisation, reflecting quite different perspectives on what counter-radicalisation and deradicalisation may entail, and the radicalisation process thereof. Narrow definitions of radicalisation characterise it as the developmental process through which an individual comes to acquire a propensity to commit acts of terrorism (Bouhana \& Wikström, 2011; Wikström \& Bouhana, in press). So defined, radicalisation is neither a necessary nor a sufficient cause of individual engagement in terrorist activity (for an in-depth discussion of this point, see ibid), nor would disengagement from terrorist activity require that an individual shed their terrorist propensity (i.e. their belief that committing acts of terrorism is a legitimate action alternative, at least under some circumstances). Indeed, the case has been made at length that physical or even emotional disengagement from terrorism does not necessarily equate or necessitate denouncement of the terrorist ideology (Horgan 2008). Within this largely criminological interpretation, 
counter-radicalisation programmes then set out to prevent individuals from acquiring a propensity for terrorism and de-radicalisation programmes would alter individuals' propensity for terrorist action (i.e. re-socialise them), rather than merely prevent or disrupt their behavioural engagement in terrorism (Fink and Hearne 2008; Horgan 2008; Horgan 2009; Schmid 2013). Whether self-styled counter-radicalisation and deradicalisation programmes aim to alter participants' terrorist propensity or simply enable their disengagement from participation in terrorist groups or terrorist activity is not always clear, however.

While deradicalisation programmes are most often aimed at those who already are members of terrorist or extremist groups, or individuals who have been imprisoned for terrorist offences, the focus of counter-radicalisation programmes is more likely to be "not the terrorists themselves but rather the strengthening and empowering of the community from which they might emerge and which might, if neglected, be deemed potentially supportive of them" (Schmid, 2013: 50). As such, counter-radicalisation initiatives will often involve working closely with communities believed to be 'at risk' and in partnership with organisations who operate locally. Along those lines, the UK government's Prevent strategy includes efforts to promote alternatives to radicalising narratives through partner organisations in Muslim communities (HM Government 2011). Such counter-radicalisation programmes may also seek to improve social cohesion, enhance resilience amongst communities through empowerment and capacity building, and encourage stronger lines of communication between government and 'vulnerable' communities (Schmid, 2013; Spalek, 2016). 
In a review of deradicalisation initiatives in the Middle East, South East Asia and Europe, Rabasa et al (2010:36) identify as more likely to be successful those efforts which "have affective, pragmatic, and ideological components that continue after the completion of the program", sustainably fulfilling the emotional, social and practical needs of participants through such interventions as counselling, helping people with finding housing and a job, or supporting the creation of new social support systems. Regarding the crucial issue of outcome evaluation, Rabasa and colleagues observe that offender rehabilitation programmes which use recidivism rates as a measure tend to make great claims of success, but whether recidivism is an appropriate gauge of evidence of deradicalisation may be questioned, especially in the relatively short term. If a programme is preventative rather than rehabilitative, then measurable indicators of success may be even more difficult to establish. Indeed, Horgan and Braddock (2010:268) note that, despite the myriad of programmes now claiming to de-radicalise participants, "(n)o such program has formally identified valid and reliable indicators of successful de-radicalization or even disengagement, whether couched in cultural, psychological, or other terms". Evaluation is often further impaired by issues of data access, given that public agencies are likely to deny independent researchers access to data on the basis of national security or the protection of information on individuals. Furthermore, most programmes are likely to have been running for a relatively short time; hence, even if it were possible to keep track of participants over a prolonged period (given, for example, anonymity requirements), insufficient time would have elapsed to capture sustained changes, if any, in the participants' criminal propensity (Rabasa et al 2010). 
Given that the UK Channel programme is described as having at once preventative (counterradicalisation), rehabilitative (deradicalisation) and behavioural (disengagement) ambitions, achieving conceptual clarity with regards to the programme's terms of reference, theories of change, desired outcomes and operational indicators of success is likely to be particularly challenging. Yet to the extent that Channel has been held up as an example for others to follow (Institute for Strategic Dialogue 2010), the programme's aims, its workings, and stated modalities of success and failure are worthy of special scrutiny.

\section{What is Channel?}

The Channel programme is designed to "identify individuals at risk of being drawn in to violent extremism, assess the nature and extent of that risk [and] develop the most appropriate support for the individuals concerned" (HM Government 2010:7). Channel is administered locally by panels made up of representatives from agencies with a relevant remit. Panels are typically chaired by a representative of the local authority and include the local Channel police practitioner (Channel Police Coordinator, Prevent Engagement Officer or Single Point of Contact), as well as members of germane statutory agencies (HM Government 2012a). These will vary across geographical areas and may include staff from, notably, youth offending services, schools, universities, health services, prisons, probation, children and adult safeguarding boards, and social services. The role of the Channel panel is "to develop an appropriate support package to safeguard those at risk of being drawn into terrorism based on an assessment of their vulnerability" (ibid:7; emphasis added).

Ultimately, it is the role of the panel chair to select an intervention package tailored to each individual referred to Channel and taken onto the programme, depending on their specific 
needs. Referrals can be made to Channel by a number of individuals, including, but not limited to, local authority staff, teachers, doctors, law enforcement personnel and social workers. As mentioned previously, the responsibility for identifying individual 'at risk' of radicalisation has recently been set in law, in such a way that teachers in primary and secondary schools, nursery workers, NHS staff, and university lecturers, among others, now have a statutory duty to assess the risk that children and young people under their care may be drawn into terrorism or may come to support extremist ideologies, including non-violent extremist creeds (HM Government 2015). Upon referral, individuals are assessed for their suitability for the Channel programme. The intervention package put in place is then delivered through statutory agencies and local intervention providers approved by the Home Office. This may require the contribution of services such as housing, employment and health services, as well as, for example, the contribution of experts in psychological counselling or faith guidance. It is not clear from publicly available documents who should be employed to provide this faith guidance or counselling, their relevant qualifications, or what this guidance would entail, although it is arguable that such knowledge is critical if members of the public and statutory agencies are expected to entrust individuals, whom they may feel the moral responsibility to safeguard, to the care of the programme.

When referred to Channel, individuals are assessed against criteria set out in the Vulnerability Assessment Framework (VAF). The VAF includes sections relating to an individual's engagement with a group, cause or ideology; to their intent to cause harm; and to their capability to do harm (HM Government 2012b). Engagement indicators include feelings of grievance and injustice, a need for identity, meaning and belonging, a desire for excitement and adventure, a desire for political or moral change, experiencing a transitional 
period in life, and any relevant mental health issues. Indicators which fall under intent to cause harm include evidence of 'us vs them' thinking, dehumanisation of an 'enemy', and attitudes that justify offending. Finally, under the capability to cause harm category, one finds such indicators as access to relevant networks, skills and competencies, relevant individual knowledge, access to funding or equipment, or known criminal capability. The VAF is made up of a checklist of 22 factors; individuals are scored from 0 to 2 on each factor and each factor score must be accompanied by justificatory evidence (HM Government 2012). Information about the design of the scale and its validation has not, to the authors' knowledge, been made openly available. Channel panels meet on a regular basis to assess the progress of each case under their purview and determine if and when an individual can leave the programme (HM Government 2015:6). It is important to note that Channel is a voluntary programme: while individuals may be referred and taken onto the programme, they do not have to comply with any assistance offered and may refuse to be involved in any way. Parental consent is required for referees under the age of 18 .

According to official figures, a total of 3,934 people were referred to Channel between 2006 and 2014 (NPCC 2016), while a recent Freedom of Information request by the BBC suggests that 3,872 referrals occurred in 2015 alone (BBC 2016a), arguably a striking rise. Children make up a significant proportion of referees, with 1,839 referrals for individuals aged 15 years and under between January 2012 and December 2015. Of these, 415 were children under the age of 10 (BBC 2016b). While these numbers are non-negligible and can be expected to rise with the rollout of the new Prevent statutory duty, it must also be noted that referral does not entail automatic acceptance onto the programme. Of the 3,934 people referred between 2006/7 and 2013/14, 777 (20\%) were eventually assessed as 
'vulnerable' and offered an intervention package (NPCC 2016). This number may raise questions about the understanding of Channel amongst those who are referring individuals or about pressures to make referrals that some staff of statutory agencies may feel they are under. To the knowledge of the authors, no public evaluation of the Channel programme exists. Reference is made (HMIC 2008) to an evaluation of the pilot scheme in 2008 by the Home Office, but this does not appear to have been made publicly available.

\section{Scoping out issues related to Channel}

While the Prevent strand of CONTEST has been the focus of much academic literature, often in a negative light (e.g. Kundnani 2009, Martin 2014, Thomas 2010), the Channel programme has not inspired as much attention, empirically or otherwise. This may be due to the inaccessible nature of data on Channel and the individuals who are adopted onto the programme (i.e. who are deemed 'vulnerable' and whose details therefore require an additional level of confidentiality), the relative newness of the programme (though it has been running since 2007), or the unwillingness by researchers or professionals working on the Channel programme to conduct, participate in or publish empirical research. Brief descriptions of Channel are given in a number of publications (Institute for Strategic Dialogue 2010, Rabasa et al 2010, Vidino and Brandon 2012), but little more is discussed beyond the structure of the programme and occasionally numbers of individuals who are referred. References are provided to official government documents regarding Channel (HM Government 2010, 2012a, 2012b and 2015), but little more detail is given.

Most recently, concerns have been raised about the roles and requirements that Prevent and Channel put upon various agencies, including social workers (Stanley and Guru 2015) 
and those working within educational establishments (O'Donnell 2015, Coppock and McGovern 2014, Durodie 2016, Brown and Saeed 2015). New statutory requirements to assess individuals for their vulnerability to radicalisation have led to questions about the conceptual understanding of radicalisation on which Prevent is based (Elshimi 2016), as well as more specific child safeguarding issues (Stanley and Guru 2015). This adds to a longstanding apprehension that Prevent and Channel are 'targeted' at certain communities, particularly those of Muslim origin, over others (O'Toole et al 2012, Coppock and McGovern 2014, Brown and Saeed 2015).

Arguably, the lack of open information about Channel is liable to feed into these and other concerns about Prevent duties: teachers, social workers, parents and others involved in the safeguarding of individuals, especially children, are less likely to feel confident enough to refer anyone under their care to the programme if they lack a basic understanding of the its aims, mechanisms and measures of success, especially given the potential for conflation between the much maligned Prevent stream of CONTEST and the Channel programme itself. This paper attempts to contribute to improving the open-source knowledge-base on Channel by presenting the findings of a qualitative study involving interviews with professionals involved in the Channel programme.

\section{Methodology}

Twelve semi-structured, in-depth interviews were conducted between January and May 2014 in the context of a larger research effort, which built upon a multilevel theory of radicalisation developed by Bouhana and Wikström (2011) to investigate the role of community-level factors, such as collective efficacy and social disorganisation, in the 
emergence of radicalising settings using agent-based modelling. Interviews were carried out with former radicals and deradicalisation experts to provide information for the modelling exercise. Six of the individuals interviewed had first-hand experience of working on the Channel programme, and it is this material which is reported upon in this paper.

One interviewee was a Channel intervention provider with expertise in far-right movements (interviewee A), while two others were intervention providers with expertise in Islamicinspired ideologies (interviewees B and F). A further three individuals (interviewees C, D and E) worked for local authorities, as members of their area's Channel team. All three had experience of organising interventions and two of them (interviewees $\mathrm{C}$ and $\mathrm{E}$ ) provided ideological interventions (in cases involving Islamic-inspired radicalisation) on behalf of their local authority. The interviewees were approached through personal contacts and snowball sampling, and all signed consent forms and were informed that their personal details would be kept confidential. Another two individuals were also approached, but due to time constraints were not available to be interviewed. It is acknowledged at the outset that the study draws from a very small, opportunity sample, and it is not suggested that these individuals are representative of the larger body of people who work on the Channel programme or that the findings gathered from the interviews are generalizable to all of Channel.

The experience of the interviewees varied, ranging from one who had worked with a dozen individuals who were referred to the programme and another with the experience of almost a hundred individuals. The geographical areas covered by the interviewees included London, the Midlands, North East, North West, South West and Wales. The interviewees were asked 
questions about a number of factors of interest that emerged from the available literature on deradicalisation programmes in other countries and questions which seemed particularly pertinent given the issues surrounding the lack of public knowledge about Channel. This included questions about the referral process, the kinds of individuals who were most suitable for intervention as part of the programme, the best time to intervene in the radicalisation process, and the importance of working with any particular statutory agencies. The interviewees were also asked for their knowledge and opinion about those practitioners who provided psychological or faith guidance on Channel, their experience and professional skills. Finally, they were asked to comment on what they considered to be the most successful and unsuccessful parts of the programme.

\section{Key themes emerging from the interviews}

Referrals

A central issue addressed during the interviews concerned the referral process, notably the threshold at which an individual should be considered vulnerable to radicalisation and referred to the Channel programme. It emerged that the threshold for referral was discretionary and differed significantly between local authorities, with interviewee $\mathrm{C}$ noting that in one area 'their threshold was incredibly low compared to ours... they would accept somebody through association'. In other words, if an individual had any association with a known radical, that was enough to justify a referral. This threshold was one which $\mathrm{C}$ wanted his local authority to adopt, noting that 'the threshold for adoption onto Channel needs to be lowered, significantly lowered'. He worried that in his area, they sometimes had to wait until they knew an individual held radical views and espoused these in public before they could 
intervene, despite being aware of their views months beforehand, stating: 'because $Y$ has never said, stated anything explicitly, you know, extreme, violent jihadi, there is no evidence to adopt them onto Channel'.

Inappropriate referrals were also an issue. While the threshold for adoption onto Channel was deemed to be too high in some areas, there were also large numbers of cases being referred to Channel that upon consideration were deemed not severe enough to be considered by the team in the local authority. In some cases, whether radicalisation was the appropriate label was in question, D stating that 'a lot of the time you get people who refer things and there's no ideology to kill, they're just nuts... so obviously it's not a Channel issue'. The low numbers of individuals referred to the programme who go on to be adopted was well illustrated in his geographical area: out of 36 referrals which took place in the two months prior to the interview, only 2 individuals went on to be adopted onto Channel. Paradoxically, this might have been because some individuals, rather than scoring low, were scoring too high on the VAF: 'Engagement, intent, capability. By the time they hit intent and they're scoring high, they're not with me, they're elsewhere' (Interviewee D). But in many cases, the scores were in fact too low. E noted that 'when I first started there were quite a few mis-referrals. And we call them pre-Channel or sub-Channel, so they wouldn't even meet the Channel threshold. But l'd still work with them, just in case.'

\section{Suitability}

The referral threshold issue was related to another concern, just as fundamental: whether the programme was suitable for some categories of individuals referred to Channel. The prevalence of mental health issues was raised by some of the interviewees, who believed 
that for such individuals, ideological change was not the problem to be addressed in priority: 'you've gotta sort out some hard core mental health issues before you can deliver [an intervention]... the mental health cases take longer to deal with than all the other cases put together' (Interviewee D). B's experience was similar: '[there] was a chap who was basically having some difficulty with mental health cases... in that one initial session [it was about] coming to the realisation that there isn't really a risk here'.

Also related to previous considerations of threshold was the notion that Channel was unsuited to dealing with individuals who had actually undergone a radicalisation process, as opposed to people who were vulnerable to radicalisation. C noted:

'I think one of the areas where we struggle, collectively struggle, is with the older individual who may be in their mid-20s or older, who has been exposed to this sort of thinking a long time... how effective can [Channel] actually be in genuinely turning them around when they've had a long long time of people telling them 'don't listen to anyone else".

He went on to discuss a situation involving multiple youths who, in his opinion, where already beyond intervention, highlighting again the limitations of the threshold standard for referral:

'Even though these girls might only be 17, 18, 19, it might already be too late. They already know what Channel and Prevent is, they've already been convinced that Channel and Prevent are, quote, enemies of Islam, and I have very serious 
doubts about the extent to which any intervention would work now... we became aware of these students a long time ago when it might have been the time, but it didn't meet the threshold so we didn't do anything'.

Such examples were provided in support of the interviewees' case for setting the threshold to 'adoption by association', whereby, instead of waiting for an individual to openly declare their commitment to radical views, their association with others who held such views would be enough to meet the Channel threshold and justify further investigation. In the view of the some of the interviewees, by having to wait, the opportunity for successful intervention might well be lost.

Youth

It came out of the interviews that young people made up a significant proportion of referrals and adoption onto Channel. According to D, '60\% [of people adopted onto Channel] will be under the age of $20^{\prime}$. In order to intervene successfully with young people, the interviewees adopted specific strategies, which leveraged pre-existing social relations in the lives of adolescents. For example, $\mathrm{C}$ explained that 'sometimes the intervention will involve working with the teachers to ensure that they are observant and responsive to any issues that may arise in the classroom, without necessarily working directly with that young person'. E stressed that forming a close relationship with young referees was key to the success of an intervention: 
'You have to have a rapport with kids and you have to build that with them... their teachers don't necessarily know [what they are talking about], and their parents don't necessarily know, then they find someone that does know and they think 'oh ok, I can talk to this adult about this and they understand what I'm trying to say'.'

\section{Schools}

Given the representation of young people among those referred to the programme, it is unsurprising that the involvement of schools in Channel was seen as crucial by the interviewees. In one East London borough, the local authority decided to invest in training provisions for teachers in all primary, secondary and sixth-form schools, so they would, it was hoped, be better able to spot some of the signs of vulnerability to radicalisation in their pupils and feel comfortable working with the Channel team during the referral process. According to $\mathrm{C}$, who created and led the training initiative, the rationale for this investment was that young people 'spend far more time with the teacher than they do with the parents'; hence, school staff would be more likely to spot behavioural indicators of vulnerability. An understanding that any referred student would not simply 'disappear into the system' went some way towards facilitating a rapport between schools and Channel. As C put it,

'the schools and colleges were much more comfortable about referring their students when they realised that the job of working with those vulnerable students would go back to them with a bit of external support if required.' 
In order to build bridges with schools and colleges, C reportedly drew upon his previouslyexisting social contacts from an earlier job within the local authority: 'This was made very easy for me cos I was a known person to the schools, to the head teachers... because I'd had this previous role on community cohesion... so essentially the doors were open for me'. He noted that having access to senior management was crucial in getting the school's backing for the Channel programme: 'I think the key thing about getting into schools was I was able to speak to head teachers'. A unique offer to the schools made the Channel team even more of a valuable resource: 'We offered a 48 hour response time to any concerns that they might have of anything related to extremism or radicalisation'. By working in the schools, with the schools, and, to some extent, for the schools - providing training to teachers and building on previous relationships - the local authority reportedly succeeded in creating strong and positive relationships with local educators.

Schools' contribution to Channel was also appreciated by $\mathrm{D}$, who noted that 'we would do quite a lot of our meetings via the school', in cases where such a setting was appropriate. It helped that students already expected 'to do what the school [told] them to do'. Likewise, $\mathrm{E}$ observed that 'schools are the best place to start because you've got your captive audience there'. While no suggestion was made that children were forced to take part, expectation that students have to comply with demands made of them on school grounds seemed to alleviate what was perceived as one of Channel's chief limitation, namely that the programme operates on a voluntary basis and referees can refuse to cooperate. 
E shared example of a case where, he believed, missed opportunities for intervention resulting from poor relationships between local authorities and schools had had real consequences:

'This young lad was picked up a couple of years ago in another borough in another school for being vulnerable to radicalisation. At that time the school didn't engage in the Channel process, didn't want to know what Prevent was, shut the door. Now this kid a couple of years down the line has moved, is come to college, same issues and concerns have come up, even? Worse, worse issues and concerns have come up. So he's had a few years to develop his views and gone from being radicalised to becoming radicaliser. Now he's got a following of girls and guys who look up to him.'

Intervention providers

The choice of intervention providers was an issue which the interviewees were particularly passionate about. The lack of accredited providers with expertise in far-right narratives was of concern for A: 'For a time there was probably only me and this other guy that's stopped doing it... police forces everywhere say we can't get anyone, so that's why I end up having to travel from Plymouth to Newcastle'. A perceived lack of competency amongst some of the providers who had been accredited was another concern: 'I've mentioned about the credibility factor, it does concern me... the guys that I've worked with, I can't picture some of the people working with [vulnerable individuals], I just can't see it happen'. This sentiment was echoed by $B$, from the perspective this time of intervention providers who counter Islamic-inspired ideology: 'Some of them are nice but I dread to think what they would do in 
a tough case scenario'. He added that 'the net result of not convincing someone [to change their extremist ideology] is the opposite, is reinforcing their point of view, and so the consequences are worse', suggesting that lack of proficiency among intervention providers could have serious consequences.

Within his local authority, $\mathrm{C}$ reported concerns over the competency levels of intervention providers accredited by the Home Office, Office of Security and Counter-Terrorism (OSCT), pointing out that 'the fact that we've done our own interventions would suggest our level of confidence in the providers that have been suggested to us'. In his previous experience of being part of a political Islamist movement, $\mathrm{C}$ had had contact with some of those intervention providers and was scathing in his opinions of them and of the process by which they became Channel providers:

'Pretty much anyone who put their hand up and said 'I can do this, I'm an intervention provider, give me money' had money... I suspected that they were trying to piggyback onto the Prevent agenda to push their own theological motives... some of these individuals have made up their back stories actually... It's one of those cases where I think in government where if you back a horse for long enough, you've gotta keep backing him forever.'

The local authority drew up a checklist of what they would expect to be on the CV of an intervention provider.

'We clearly saw that the people who are currently being funded wouldn't have got the job 
because they had nothing other than saying 'I can do it'... they hadn't come from a teaching background, a social work background, they weren't, you know, from a theological point of view recognised scholars.'

Consequently, C's local authority chose to adopt a different strategy from that taken elsewhere: 'There is expertise within our schools, within local authority, and we think the best way to do it is to utilise what we've got'. C thought that this approach was particularly worthwhile when it came to encouraging those who worked within the education sector in the local authority to collaborate with them on Channel. Nevertheless, this led to difficulties when trying to fit the approach into governmental mechanisms: 'The Home Office would not accept us as intervention providers. They would not accredit us'. This meant difficulties with regards to funding provision, as well as the recognition of expertise and training provision.

\section{Training}

The training given to intervention providers was another point of contention. Notably, the level of training received by Channel providers varied. Not only did A reportedly receive no training, he was asked to provide training to others. While his experience was not in question, as he had worked for over 20 years providing counter-narrative support for interventions targeted at the far-right, A stated that he had his involvement in Channel was not accompanied by further professional development. Conversely, as a provider of interventions to counter Al-Qa'ida-inspired radicalising narratives, B was involved in a more comprehensive training programme: 'We were sent on a particular course at Al Ansar University that looked specifically at the remit of jihad... and we do have a regular seminar where we share best practice and training'. Also mentioned was skill-specific training when 
it came to implementing the VAF: 'The Home Office did make an attempt to train us on how to develop that way of thinking and how to make that type of analysis on what the [vulnerability] factors are'. However, he remained sceptical about the amount of expertise within Channel as a whole, stating:

'One of the criticisms that I have... is the absence of expertise at all levels and in all aspects of those who are supposedly working on it... the vast majority of my colleagues don't know anything about this... some people have done a sort of short course in Kings [College London] on this, on radicalisation.'

From the perspective of those interviewees who worked for local authorities, rather than as independent intervention providers, the picture was also mixed. D noted that he had received 'a lot of training on Islamist [ideologies]... there's a lot of in house training going on. I mean for instance I went on a mental health course', while, when asked whether he had received Channel-specific training from the Home Office, C replied 'no, no not at all'. However, within his remit in his local authority, C reported that he had adapted one of the Home Office training programmes on Channel to deliver to teachers in local schools. While this was well received by the majority of teachers, he observed that:

'We have had issues with individual teachers who have been extremely hostile to the Prevent agenda... who come from the political far-left who are offended on behalf of Muslims... Some of the hostility was simply expressed by a sort of sullen silence and negative body language. Other times open hostility with loud criticisms and loud accusations during the training itself.' 
C thought that this kind of hostility from some teachers was particularly concerning, as it might plausibly reflect on their willingness to refer vulnerable young individuals in their care to the Channel programme. He added, 'When you think these are teachers responsible for, you know, looking after young people, it's still more than we'd like to have seen to be honest.'

\section{Summing up Channel's perceived strengths and weaknesses}

All six interviewees were asked for their take on strengths and weaknesses of Channel, examples of which have been touched on in the context of specific issues discussed above. Building a partnership with schools and using existing relationships where possible, alongside with having a captive audience in those places, were all perceived as strengths of the programme. The ability to empathise with the children in these settings and having the knowledge to engage with them on those issues that mattered to young people was also reportedly essential to the success of interventions. This last point touches on the issue of the credibility of intervention providers; those providers who believed that they occupied a credible role claimed to have used it to their advantage. One interviewee thought that his fashion sense and knowledge of the punk music scene granted him with a degree of believability with young people, as well as provided him with a talking point to 'break the ice'. For another, his status as a former member of an extreme Islamist group and his detailed knowledge of Al-Qa'ida-inspired narratives were the foundations of his authority and trustworthiness amongst those with whom he intervened. Credibility, or lack thereof, was one oft-reported source of concern among others, such as lack of accreditation and 
training, having to do with intervention providers put forward by OSCT. Interviewees felt that much remained to be done to ensure that all Channel intervention providers could demonstrate genuine expertise, while in other cases the seeming inflexibility of OSCT when it came to accredit in-house, local authority experts was perceived as a weakness.

The holistic approach to interventions made possible by the panel mechanism was one of the programme's main strengths according to many of the interviewees. By having representatives of various arms of the local authority on the panel, it was possible to get help for individuals regarding housing, employment or benefits, substance abuse, healthcare and education, as well as any counselling or ideological intervention, all of which could contribute to address radicalisation concerns. This was particularly important in the case of individuals with mental health issues, as previously highlighted. This inclusive approach was also instrumental in targeting interventions, regardless of which activity or activities, such as participation in sports or music, was thought to present opportunities for radicalising exposure given the individual's lifestyle. The ability to tailor each intervention package to the specific needs of the individual, rather than employing a one-size-fits-all approach, was seen as essential by all the practitioners interviewed. What proved perhaps more divisive, in the sense that some interviewees noted it as a strength and others a weakness, was the involvement of law enforcement officials in the Channel panel. While C thought that 'some of the successes of Channel are... that individuals realise that they've drawn attention to themselves, that a police officer's phoned them up and they are then inclined to pull their necks in, as it were', D stated that 'if I was to turn around and say what do you consider to be a contribution towards some failures, it's the ones where [the Police] had to knock on the door'. 
Holistic approach notwithstanding, it seems that interventions of a theological nature formed the core of packages offered by Channel in many cases, which raised some concerns among some of the interviewees. For example, C observed that what individuals needed were 'activities that [gave] them an alternative to religion rather than more but slightly different religion, and I think that for a large part of the time, Channel has an undue focus on theological sort of interventions', hereby failing to provide young people with 'something else to do which doesn't involve him obsessing about religion all the time'. The feeling was that, to be successful, intervention should address a range of needs far beyond the moral and spiritual.

Regardless of the type of intervention package, early intervention was perceived as a vital factor of success. Several interviewees deplored those cases where early intervention had been impossible and they had to work with individuals who had already been radicalised, some for a considerable period of time. Part of this failure to intervene in time was attributed to the threshold for referral and adoption onto Channel being too high, especially in some geographical areas as compared to others. As noted by $\mathrm{C}$ with regards to one case of group radicalisation in the school environment, having to wait until radical sentiments were expressed in public compromised the possibility of successful intervention. This difficulty is compounded by the voluntary nature of Channel. In the words of C: 'Where they won't engage, what happens then?' A noted that there had been 'a few failures where either they don't want to engage or they're just impossible to engage with', but when questioned as to whether he thought engagement with Channel should be made compulsory, his view was that he 'could swing either way with that'. 


\section{Discussion}

Beyond some basic data on individuals referred to the programme, general descriptions of the referral process, and information on the criteria which makes up its Vulnerability Assessment Framework, concrete details on the workings of Channel remain scarce. Training and accreditation of intervention providers, adoption thresholds, and contents of intervention packages are all issues raised by our interviewees which would benefit from lengthy, empirical investigation, not to mention a systematic evaluation of Channel's outcomes. The operation of Channel appears to vary quite significantly between different local authorities, which raises the question of what context-specific factors may influence the more or less efficient and effective implementation and delivery of the programme. More fundamentally, the lack of information on Channel leaves unanswered essential questions, such as how intervention success is measured in tangible terms, whether shortterm or long-term, what are the consequences of intervention for individuals adopted onto the programme, both intended and unintended, and whether the programme actually delivers on its promise to reduce the incidence of radicalisation in the UK, and, ultimately, the incidence of terrorism.

Independently of how these questions can be dealt with, further clarification, or perhaps more properly reframing, of the programme's objectives may be necessary. Our interviewees repeatedly stressed that Channel was an early intervention programme, unsuited to individuals who have already radicalised. This makes it clear that, contrary to its portrayal, notably in the media (e.g. BBC, 2016a, 2016b), Channel is not a deradicalisation initiative; rather, it is a counter-radicalisation programme. This is not a matter of pedantry: 
if the purpose is to deradicalise, then the mechanisms that interventions should leverage are those which bring about propensity change, while, if the purpose is to prevent radicalisation altogether, then the relevant mechanisms are those that will bring about resilience to propensity change. A clear grasp of the categories of causal factors and processes involved at these different stages of individual moral development will be essential to successful intervention design and delivery of stated objectives (Wikström and Bouhana, in press). Appropriate framing will also be key in communicating effectively with those stakeholders that Channel, and more broadly Prevent, aim to partner with.

When considering the issue of embedding prevention within the police service and wider agency partners, this raises a number of issues. To the extent that, legal duty notwithstanding, those partners are more likely to be well-disposed towards Prevent and Channel if they trust the authorities who deliver interventions, and, furthermore, to the extent that such trust is unlikely to thrive in the absence of open-source information, educating partners and communities about Channel may be a prerequisite for the effective implementation of the new statutory duty. Community members will play a key role in this implementation as, for example, parents are likely to play some part in encouraging schools to cooperate with their local authority on the issue of radicalisation prevention. In turn, schools - which, our interviews suggest, are vital Channel partners - could be reasonably expected to only be willing to work closely with those tasked with delivering the programme if they are confident that Channel's priority is to safeguard children and youths, and that referral will not further stigmatise potentially vulnerable and marginalised individuals or groups. As our interviewees suggested, teachers naturally protective of their pupils are more likely to be willing to refer them to a programme that may have a great deal of impact 
on the children's future if they are provided with information as the programme's workings, the qualifications of providers, and ways in which they can remain informed and involved in the progress of child's case. If it is at all possible to undo the damage done to the Prevent brand, and by association to Channel's image, then arguably this will require as much transparency as the demands of individual protection allow, as well as the leveraging of preexisting, positive (likely interpersonal) relationships between local authority and educational institutions. While it may be that one way to improve the uptake of the new Prevent duty and ultimately the efficiency of Channel would be to divorce the programme from its association with counter-terrorism and repackage it as a more mainstream social support initiative, this seems quite unlikely in the current socio-political context.

Improved communication with partner audiences, of course, is rarely enough. Material gains, in terms of intervention providers' qualification, accreditation and training, must be achieved across the geographical board. Questions of appropriate referral thresholds, or whether intervention packages should privilege spiritual, ideological, or socio-cognitive support, or all three, can ultimately only be settled through continued improvement of the scientific knowledge-base on radicalisation.

\section{References}

BBC (2016a) ‘Deradicalisation programme referrals on rise', accessed 17/03/2016 http://www.bbc.co.uk/news/uk-34469331 
BBC (2016b) 'More than 400 children under 10 referred for 'deradicalisation', accessed 17/03/2016 http://www.bbc.co.uk/news/uk-35360375

Bouhana, N. \& P-O H. Wikström (2011). Al Qa'ida-Influenced Radicalisation: A Rapid Evidence Assessment Guided by Situational Action Theory. Occasional Paper 97. Research, Development and Statistics, Office for Security and Counter-Terrorism. London: Home Office

Brown, K. E. and Saeed, T. (2015) 'Radicalization and counter-radicalization at British universities: Muslim encounters and alternatives', Ethnic and Racial Studies, 38:11, 19521968

Coppock, V. and McGovern, M. (2014) “Dangerous Minds'? Deconstructing CounterTerrorism Discourse, Radicalisation, and the Psychological Vulnerability of Muslim Children and Young People in Britain', Children and Society, 28, 242-256

Durodie, B. (2016) 'Securitising Education to Prevent Terrorism or Losing Direction?' British Journal of Education Studies, 64:1, 21-35

Elshimi, M. (2016) 'Prevent 2011 and counter-radicalisation: What is deradicalisation', in Baker-Beall, C., Heath-Kelly, C. and Jarvis, L. (eds) Counter-Radicalisation: critical perspectives, Routledge, London and New York, pp 258-276

Fink, N. C. and Hearne, E. B. (2008) Beyond Terrorism: Deradicalization and Disengagement from Violent Extremism, International Peace Institute, available at 
https://www.counterextremism.org/resources/details/id/194/beyond-terrorismderadicalization-and-disengagement-from-violent-extremism

HM Government Counter-Terrorism and Security Act 2015 Section 26

HM Government (2010) Channel: Supporting individuals vulnerable to recruitment by violent extremists, March 2010 http:/security.homeoffice.gov.uk/newspublications/publication-search/prevent/channel-guidance?view=Binary

HM Government (2011) Prevent Strategy, available at http://www.homeoffice.gov.uk/publications/counter-terrorism/prevent/prevent-strategy/

HM Government (2012a) Channel: Protecting vulnerable people from being drawn into terrorism. A guide for local partnerships, October 2012, available at www.npcc.police.uk/documents/TAM/2012/201210TAMChannelGuidance.pdf $+\& c d=7 \& h l=e$ $n \& c t=c|n k \& g|=u k$

HM Government (2012b) Channel: Vulnerability Assessment Framework, October 2012, available at https://www.gov.uk/government/publications/channel-vulnerabilityassessment

HM Government (2015) Channel Duty Guidance: Protecting vulnerable people from being drawn into terrorism, available at https://www.gov.uk/government/publications/channelguidance 
HMIC (2008) Preventing Violent Extremism: Learning and Development Exercise, Report to the Home Office and Communities and Local Government, October 2008, available at www.justiceinspectorates.gov.uk/hmic/media/preventing-violent-extremism-learning-anddevelopment-exercise-20080930.pdf $+\& c d=1 \& h l=e n \& c t=c l n k \& g l=u k$

Horgan, J. (2008) 'Deradicalization or Disengagement? A Process in Need of Clarity and a Counterterrorism Initiative in Need of Evaluation', Perspectives on Terrorism, 2:4, 3-8

Horgan, J. (2009) Walking away from terrorism: Accounts of disengagement from radical and extremist movements, London, Routledge

Horgan, J. and Braddock, K. (2010) 'Rehabilitating the Terrorists?: Challenges in Assessing the Effectiveness of De-radicalization Programs', Terrorism and Political Violence, 22, 267291

Institute for Strategic Dialogue (2010) The Role Of Civil Society In Counter-radicalisation And Deradicalisation. A Working Paper Of The European Policy Planners' Network On Countering Radicalisation And Polarisation (PPN), available at https://www.counterextremism.org/resources/details/id/6/ppn-working-paper-the-role-of$\underline{\text { civil-society-in-counter-radicalisation-and-deradicalisation }}$

Kundnani, A. (2009) Spooked! How not to prevent violent extremism, Institute of Race Relations, October 2009 
Martin, T. (2014) 'Governing an unknowable future: the politics of Britain's Prevent Policy', Critical Studies on Terrorism, 7:1, 62-78

NPCC (2016) accessed 17/03/2016

http://www.npcc.police.uk/FreedomofInformation/NationalChannelReferralFigures.aspx

O'Donnell, A. (2015) 'Securitisation, Counterterrorism and the Silencing of Dissent: the Educational Implications of Prevent', British Journal of Educational Studies, DOI:

$10.1080 / 00071005.2015 .1121201$

O’Toole, T., Nilsson DeHanas, D. and Modood, T. (2012) ‘Balancing tolerance, security and Muslim engagement in the United Kingdom: the impact of the 'Prevent' agenda', Critical Studies on Terrorism, 5:3, 373-389

Rabasa, A., Pettyjohn, S. L., Ghez, J. J. and Boucek, C. (2010) Deradicalizing Islamist Extremists, RAND, available at www.rand.org/content/dam/rand/pubs/.../2010/RAND_MG1053.pdf

Schmid, A. P. (2013) Radicalisation, Deradicalisation, Counter-radicalisation: A Conceptual Discussion and Literature Review, Hague, International Centre for Counter-Terrorism Spalek, B. (2016) 'Radicalisation, deradicalisation and counter-radicalisation in relation to families: Key challenges for research, policy and practice', Security Journal, 29:1, 39-52 
Stanley, T. and Guru, S. (2015) 'Childhood Radicalisation Risk: An Emerging Practice Issue', Practice: Social Work in Action, 27:5, 353-366, DOI: 10.1080/09503153.2015.1053858

Thomas, P. (2010) 'Failed and Friendless: The UK's 'Preventing Violent Extremism' Programme', The British Journal of Politics and International Relations, 12, 442-458

Vidino, L. and Brandon, J. (2012) 'Europe's experience in countering radicalisation: approaches and challenges', Journal of Policing, Intelligence and Counter Terrorism, $7: 2,163-179$

Wikström, P-O H. \& N. Bouhana (2016). "Analyzing radicalization and terrorism: A Situational Action Theory." In LaFree, D. and Freilich, J.D. (Eds.), Wiley Handbook of the Criminology of Terrorism. Wiley. 